\title{
Improvement of CRM using Data Mining: A Case study at Corporate Telecom Sector
}

\author{
Sanjib Kumar Routray \\ Research Scholar, Utkal \\ University \\ Bhubaneswar, Odisha, India
}

\author{
Sanjit Kumar Dash \\ College of Engineering and \\ Technology \\ Bhubaneswar, Odisha, India
}

\author{
Sasmita Mishra \\ Indira Gandhi Institute of \\ Technology \\ Saranga, Odisha, India
}

\begin{abstract}
As Customer relationship management (CRM) is a well established concept and its practice to enable the realization of successful Telecommunication system, data mining techniques is developed for improving the customer relationship management part mainly in Corporate Telecom Sector. Considering the existing methodology, a well established methodology with data mining is needed for development of good integrated approach with growth in time and space complexities. The aim is to find the strategic point on the essential part of Telecommunication industry by exploring the techniques of data mining. Then the focus is on presenting a new methodology in case of mobile services on the perceptions of customers of Telecommunication basing on applicability of data mining techniques to CRM databases by generating Association rules from frequent item sets on the proposed approach F-MFPG (Fast Modified Frequent Pattern Growth) by using FFIM (Fast Frequent Item sets Mining) Algorithm under concept of data mining and predicting the profit of Corporate Telecom Sector and predicting the churn for retention of customers for efficient managerial decision for reaching the ultimate goals by proposing a suitable classification techniques in data mining algorithms.
\end{abstract}

\section{Keywords}

Customer relationship management, Fast Modified Frequent Pattern Growth, Fast Frequent Item sets Mining, Association, Classification, True Positive, False Positive and Telecommunication

\section{INTRODUCTION}

Telecommunication is the fastest growing corporate service sector, which offers quality of services with new technology for attracting new customers and retaining existing customers while competing with private sectors to defend their positions in the market through maintaining the customer relationship management [5]. After exposure of market to wire line and wireless and growing competition among private sectors, sometimes corporate sectors facing serious problems on wire line and wireless service with its drop from number one position to a loss making of fourth makes the analysis more significant. Accordingly corporate Telecom Sector should examine the different issues of customer relationship management for enhancing the customer relations. Thus to ensure greater reliability and throughput, implementation of data mining techniques in large CRM data sets of Telecom corporate sector is highly essential. Two major points is proposed in data mining i.e. generation of association rules from CRM frequent item sets by FFIM algorithm and prediction of churn by suitable classification algorithms by using WEKA for analyzing the customer buying behavior and retaining the existing customer to offer the best customers demand combo service.

\section{LITERATURE REVIEW}

The main objective of research is to examine the targeted marketing through data mining technique and its determinants for establishing a theoretical basis and identifying research gap, which will allow the study to hypothesize the linkage among the different constructs currently acknowledged to affect managerial decisions and outcome of targeted marketing.

\subsection{CRM in Telecom Sector}

Bagozzi et. al [4] in his article entitled, "Reflections on Relationship marketing in consumer markets" has pointed out that customer orientation and customer retention is the main focus point under various definitions of customer relationship marketing. Previous research has compared consumer's service quality expectations across services, but for each different service, different groups of subjects have been evaluated. The problem of using different subjects for each service is that the subject's significant differences in expectations of quality depend on demographic characteristics. Further in the article "Relationship Marketing" that relationship marketing to direct marketing, attention towards customer as relations, customer retention or assets but not targets for attracting maintaining and enhancing customer relationship for long term marketing success [5].Then question arises on "Customer Satisfaction Measurement" which is nothing but the success of the product or service in the market depends on customer's perception towards service and quality of a product determines. With better understanding of customer's perceptions, a firm can determine the suitable actions to meet the needs of customers. Firms can identify their own strengths and weaknesses opportunities and threats in comparison with their competitors. Customer loyalty is an important strategic objective for all organizations. Product quality, price, packaging, responsiveness and ability to resolve complaints are the main attributes for influencing customer satisfaction [6]. At present the most important consumer segments is the cellular market in the business class segment and youth segment. As the competition in telecom area intensified, service providers have taken new initiatives to customers through loyalty rewards, discount coupons, business solutions and talk time schemes for maintaining good customer relationships [7]. Sasikala et. al [13] in her article titled, "Telecom Services: Measurement of Customer Satisfaction" has indicated that service quality includes elements, like network coverage, connectivity and voice clarity which are strongly correlated with the technical constraints of the mobile subscriber network as well as service providers own infrastructure. Further customers set reliability among all the components of service quality is also the important criterion to determine behavioral intention. Accordingly reliability and responsiveness are two important distinctive quality factors between satisfied and dissatisfied customers. But basic 
problems An Exploratory study have pointed out that the basic problems faced by telecom sector are increasing competition, emerging markets, retaining customers, government regulations and maintaining cost i.e. due to growing competition, the existing customers may switch over to other connections which may be highly beneficial compared with the existing ones. Telecom Regularity Authority of India (TRAI) norms is stringent and the service providers find it difficult to meet the norms as per government regulations according to [14] in the paper entitled "Role of Competition in Growing Markets: Telecom Sector. Adam et. al [1] stated that telecom service provider even in United States faced a sea of troubles. US wireless carriers is challenging and can no longer grow by acquiring new customers; in fact, their new customers are likely to be migrated from other carriers. Indeed, churning will account for as much as $80 \%$ of new customers in 2005 . At the same time, the carrier's Average Revenue Per User (ARPU) is falling.

Many Telecommunication companies faced only one thing i.e. need to manage a customer relationship in electronic age, for profit is a marketing dilemma. Various reasons of stemming growth can be rising subscriber base, rising teledensity, rising handset requirements, saturated telecom markets of other countries, stiff competition, requirement of huge capital, high growth curve on telecom, changing regulatory environment, conducive FDI limits in telecom sector. With stiff competition between the operators, customer satisfaction is a necessary for market survival. Many telecommunication service operators are offering various combo products and value added services in the market. Further customer perception is a personal feeling of either pleasure or disappointment resulting from the evaluation of service provided by an organization to an individual in relation to expectations as it is highly essential and inevitable for the smooth functioning of an organization having public dealing and responsibilities [11].

\subsection{Data Mining in Telecom Sector}

In the paper [16] "Review the Literature of Data Mining", literature of Data mining technique is reviewed such as Association Rules, Rule Induction Techniques, Apriori Algorithm, Decision Tree \& Neural Networks for using different application areas for finding out meaningful patterns from the database i.e. by improving effectiveness of managerial decision -making. To analyze, manage and make a decision of such types of huge amount of data. Data mining Technology needed for transformation into many fields ."A Recent Survey on Incremental Temporal Association Rule Mining" paper stated that, various methods for incremental as well as temporal association rule mining. Algorithms were based on dividing temporal databases rules by finding frequent item sets within their partitions by comparing between different methods in respect to scanning, nature of dataset \& performance [12]. Further on recent survey Improved Classification Based Association Rule Mining [12] designed by Author i.e. the Integration of two techniques Association rules \& Classification techniques of data mining in knowledge discovery process \& produced a new approach called Class Association rule Mining which provides better classification accuracy in classifying the data .This paper proposed for two algorithms i.e. CMAR(Classification based on multiple class Association rule) \& CPAR(Classification based predictive Association rule. From the extensive experiments, it is observed that CMAR is constituent \& highly effective in terms of memory requirements, time complexity.

On the analysis of the existing Data mining Techniques in computer Relation Management, different predictive \& descriptive techniques such as Association rule, Clustering \& Classification analyzed and also described how these techniques were used to improve the customer relationship with the company which leads a considerable profit. "Optimizing the CRM process in Product Market place by Association Rule Mining Technology" paper where, author stated that optimized the CRM process by three steps of business practice "Measure", "Product" \&"act" as a cycle of CRM by continuously improving by effective tools like Association rule Mining [2]. In the paper "Data mining Techniques for CRM", where author analyzed the current scenario where companies interact with their customers changed dramatically over a past few years. As a result companies have found that they need to understand their customers better \& to quick respond to their wants $\&$ needs in time frame [15]. Paper of [3] i.e." Proposed ranking for point of sales using data mining for Telecomm operations" helps Telecomm companies in making decisions that optimize the sales points to reduce costs and also to identify profitable customers and churn one."Customer churns prediction in Telecommunication Industry using Data mining technique-A Review" paper predicts that Customer churn prediction is a foremost feature of a contemporary telecom CRM system. Churn prediction prototype guides the customer's relationship management to retain the customers who are probable to quit [8]. In recent epochs no. of supervised data mining techniques $\&$ classification are used to model the churn prediction. These articles reviewed the various methods of churn prediction with reference to Telecommunication Company. A plethora of big data application are emerging \& being researched in the computer science, which requires on line classification pattern recognitions of huge data pools collected from various sources. As traditional data mining techniques are facing lot of difficulties, novel algorithms are used for knowledge discovery through statistical analysis and subsequent analysis of organization structure with network graphical pattern with the knowledge machine learning methodology efficiently [9]. Telecom companies not only focusing on customer's profitability to increase their market share but also on their potential churn customers who could terminate the relation with the company in near future. Big data promises to promote growth and increase efficiency and profitability across the entire value churn by segmenting into high value customers and potential churn customers through RCM (Recently frequency Monetary) analysis and targeted by offering on basis of their similar characteristics. Recent literature related to use of data mining for CRM based on review of contemporary literature, it is studied that data mining techniques employed in different type of business, Corporate sector \& organization to manage company relation with the existing and prospect customers for forecasting and decision making [10].

\section{PROBLEM STATEMENT}

In a fast developing country Telecom Corporate Sector is growing like any things. But at present the complex situation faced by Telecom Corporate Sector with its drop from number one position to a continuous loss making fourth position and losing market share with incurring financial losses. Management seriously thinking to come out of monopolistic mold and planned the organization structurally and operationally through Projects developed for enhancing 
customer relations, strengthening technology and upgrade infrastructural assets. During the study of Odisha Circle of Telecom Company, it is observed that, with the technology development and skilled development of internal employees the present practice of Customer Relationship Management has gained significance. Accordingly present study of CRM with issues analyzed in one module of CDR Data Centre and proposed to examine CRM issues through data mining techniques implemented and tested through new proposed algorithms by using open source software like MATLAB and WEKA in data sets by Company for enhancing customer relations operationally to exploit strength of largest base of existing customers as well as implementing the quick decision of management for growing profit.

\section{PROPOSED FAST MODIFIED FP- GROWTH APPROACH (F-MFPG)}

Traditional Apriori algorithm involves expensive candidate generation process for mining the complete set of frequent item set. Hence an interesting method attempted called frequent pattern growth approach or simply FP Growth, where divide-and-conquer strategy adopted instead of generate-andtest of Apriori. In this method, first database will be compressed for representing frequent items into frequent pattern tree, which retains the item set association information. Second it divides the compressed database into conditional database, each associated with one pattern fragment that mines each database separately. Traditional Apriori algorithm involves expensive candidate generation process for mining the complete set of frequent item set. Hence an interesting method attempted called frequent pattern growth approach or simply FP Growth, where divide-andconquer strategy adopted instead of generate-and-test of Apriori. In this method, first database will be compressed for representing frequent items into frequent pattern tree, which retains the item set association information. Second it divides the compressed database into conditional database, each associated with one pattern fragment that mines each database separately. Out of different methods of mining association rules, FP-Tree is the latest method, where entire transactional datasets converted into a compact prefix tree structure. The path/branch of a FP-Tree is the representation of individual transaction and FP-Tree removes various shortcomings of traditional association rule mining methods. But fast proposed modified FP-Tree (FMFPG) is highly condensed, which removes all shortcomings of traditional FP-Tree (1) expensive multiple scanning (2) Unnecessarily traversal of complete tree, while checking the particular node in the tree.

\section{A. Reduced Header Table}

Proposed reduced header table only keeps the items with their corresponding frequencies, which are already present in the FP-Tree according to descending order of support. The main advantage of reduced header table is all the items in the transactional data sets may not present always in the header table, in comparison to traditional header table of FP-Tree.

\section{B. Auxiliary Tree}

Auxiliary Tree is the third type of data structure, where existence of node item name and their node count of same item in the proposed modified FP-Tree. Initially auxiliary tree will be constructed, where 2 nd most frequent item will be the root node and other node, whose frequencies on descending order will be child node correspondingly. Starting from root node to end node, node-count will be initialized to zero initially. There are only two cases, when items in the individual transaction will be added to auxiliary tree.
(1) When the most frequent item is not present as first element of individual transaction, all transactional node item will be added in auxiliary tree as a result node-count will be incremented.

(2) When there is no direct link between the current root and item in consideration and also exist in the FP-Tree, then all the following items in the transaction will be added to auxiliary tree as a result node count will be incremented.

\section{Algorithm-1. Main Modified FP-Tree, Reduced Header Table \& Auxiliary Tree. \\ INPUT: Transaction Database}

OUTPUT: Main Modified FP-Tree, Reduced Header Table \& Auxiliary Tree

1. List out all items in the transaction dataset \& find its Support for each item.

2. Declare the minimum support threshold and remove the item from list, which do not have minimum threshold.

3. Identify the most frequent item in the transaction dataset \& for each transaction in the dataset sort the individual transaction based on the support in a descending order.

4. Create a root node which is referred to as Original root of a main modified FP-Tree.

5. Set the original root as current root for each transaction of main-modified FP-Tree.

6. Create a root node as 2 nd most frequent item from list of the items of Auxiliary Tree. Other child items exist in order of decreasing support correspondingly $\&$ initialize node counts of all items to zero.

7. Let the first item in each transaction be " $\mathrm{X}$ " and remaining be " $\mathrm{Y}$ "e.

8. If " $\mathrm{X}$ "e is the most frequent item

9. If " $\mathrm{X}$ "e is not child of current root of main modified FP-Tree

10. Create " $\mathrm{Xe}$ as the child of current root

11. Make count of the first item in reduced header table as 1 .

12. Make the newly created node as current root

13. Else Make " $\mathrm{X}$ "s node as the current root

14. Increment the count of " $\mathrm{X}$ " in reduced header table

15. For all frequent items " $\mathrm{Y}$ "e when " $\mathrm{X}$ "e is the most frequent item

16. If " $y$ "exists as a child of current node

17. Increment the count in the reduced header table

18. Move the current root to the child node

19. Else If " $\mathrm{Y}^{\mathrm{ee}}$ is not present in the reduced header table

20. Create a new node for " $\mathrm{Y}$ "e as the child of current root

21. Make the count of corresponding item in the reduced header table as 1 . 
22. Make the newly created node as current root

23. Else Increment the node count of remaining item in Auxiliary tree

24. Else Increment the node count of all the items in the Auxiliary tree.

\section{Algorithm-2. Fast Frequent Item sets Mining}

INPUT: Modified FP-Tree, Reduced Header Table, Auxiliary Tree

Output: Items set " $\mathrm{A}^{\text {ee }}$ containing all frequent item set with their corresponding frequencies

1. Initially " $\mathrm{A}^{\mathrm{ee}}$ is empty for all items in the reduced header Table

2. $\mathrm{S}=$ User declared minimum support threshold

3. $F=$ Frequency of the item in reduced header table

4. Auxiliary Node count as AN Count $=$ count in the node item of Auxiliary tree

5. If $\mathrm{F}$ is not equal to $\mathrm{S}$

6. If $\mathrm{F}$ is greater than $\mathrm{S}$, frequency of frequent item set is $\mathrm{FF}=\mathrm{F}$

7. Else frequency of frequent item set is $\mathrm{FF}=\mathrm{F}+\mathrm{AN}$ Count

8. Generate all maximum possible combination of the current item and all the nodes up to most frequent item node in modified FP-tree and then to " $A^{\text {ce }}$ with their frequencies as $\mathrm{FF}$

9. Else frequency of frequent item set is $\mathrm{FF}=\mathrm{F}$

10. Generate all possible combination of the current item and all the elements present at the lower index than the current item's index in the reduced header table

\section{SIMULATION AND RESULT}

One real datasets of CRM modules of Telecom Company with selecting ten important attributes of 120 instances (Transactions) tested with Traditional FP-Algorithm for generating the FP-Tree through MATLAB in system with above specification. While implementing, important attributes chosen with class attribute for generating the frequent item sets with subsequent generation of association rules in phase by phase. For example, we have chosen, CATEGORY \& PLAN, where for data item LIG, MIG \& HIG under CATEGORY attribute with various plan like PREPAID-FRC46, PREPAID-FRC-100, FRC-35 under PLAN attribute. From the testing of various categories we find no. of association rules. One result has been shown under LIGCATEGORY for different plans under heading 1,2,3..upto 6.(implemented at coding phase). As per snapshot diagram Fig-1, resultant output of Traditional FP-Growth shows that most occurring frequent pattern is $2 \& 6$. Association rule as accepted is $2 \rightarrow 6$ (Confidence above minimum threshold). Similarly we can find out frequent pattern for MIG \& HIG CATEGORY.

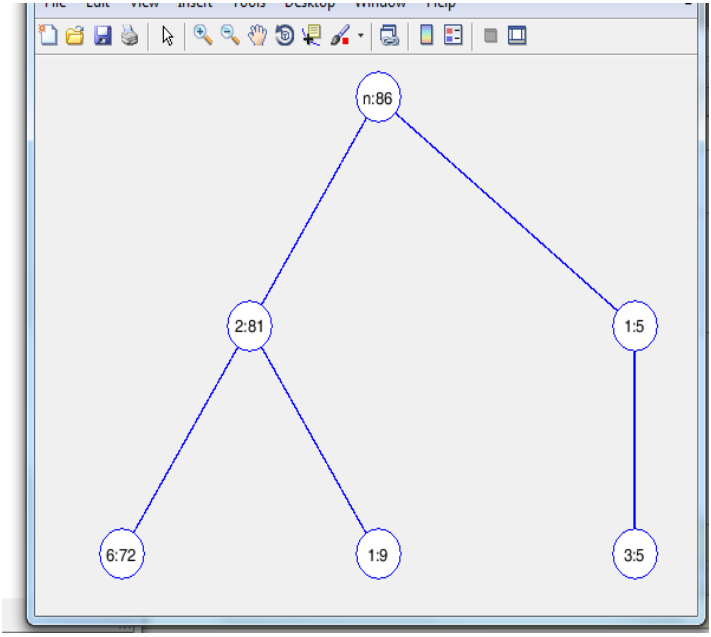

Fig. 1 Tree output of Traditional FP-Growth tree

Further our proposed algorithm implemented through MATLAB by using same attribute under same category for same data sets of 120 transactions. As per snapshot diagram Fig-3, resultant output of Proposed Fast Modified FP-Growth algorithm shows that most occurring frequent pattern is $2 \& 6$. Association rule as accepted is $2 \rightarrow 6$ (Confidence above minimum threshold). Similarly we can find out frequent pattern for MIG \& HIG CATEGORY.

\begin{tabular}{|c|c|c|c|c|}
\hline \multicolumn{5}{|c|}{$\begin{array}{l}\text { Profile Summary } \\
\text { Generated 30-Mar-2018 20:47:11 using performance time. }\end{array}$} \\
\hline$\underline{\text { Function Name }}$ & $\underline{\text { Calls }}$ & Total Time & $\underline{\text { Self Time }}^{*}$ & $\begin{array}{l}\text { Total Time Plot } \\
\text { (dark band = self time) }\end{array}$ \\
\hline$\underline{\text { main }}$ & 1 & $8.346 \mathrm{~s}$ & $0.238 \mathrm{~s}$ & I \\
\hline$\underline{\text { PlotTree }}$ & 1 & $6.881 \mathrm{~s}$ & $0.566 \mathrm{~s}$ & 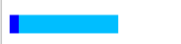 \\
\hline$\underline{\text { hold }}$ & 6 & $3.666 \mathrm{~s}$ & $3.645 \mathrm{~s}$ & ש \\
\hline$\underline{\operatorname{axis}}$ & 1 & $2.335 \mathrm{~s}$ & $2.334 \mathrm{~s}$ & C \\
\hline FPGrowth & 1 & $1.015 \mathrm{~s}$ & $0.401 \mathrm{~s}$ & $\mathbf{I}$ \\
\hline union & 86 & $0.224 \mathrm{~s}$ & $0.023 \mathrm{~s}$ & I \\
\hline dec2binvec & 10 & $0.216 \mathrm{~s}$ & $0.055 \mathrm{~s}$ & I \\
\hline union> unionR2012a & 86 & $0.201 \mathrm{~s}$ & $0.082 \mathrm{~s}$ & I \\
\hline treelayout & 1 & $0.193 \mathrm{~s}$ & $0.164 \mathrm{~s}$ & I \\
\hline GetPowerSet & 5 & $0.172 \mathrm{~s}$ & $0.044 \mathrm{~s}$ & I \\
\hline unique & 86 & $0.118 \mathrm{~s}$ & $0.041 \mathrm{~s}$ & | \\
\hline ismember & 430 & $0.117 \mathrm{~s}$ & $0.019 \mathrm{~s}$ & | \\
\hline der.2hin & 10 & $011 \mathrm{hs}$ & $0116 \mathrm{~s}$ & 1 \\
\hline
\end{tabular}

Fig. 2 Snapshot of MATLAB output of Traditional FPGrowth tree 

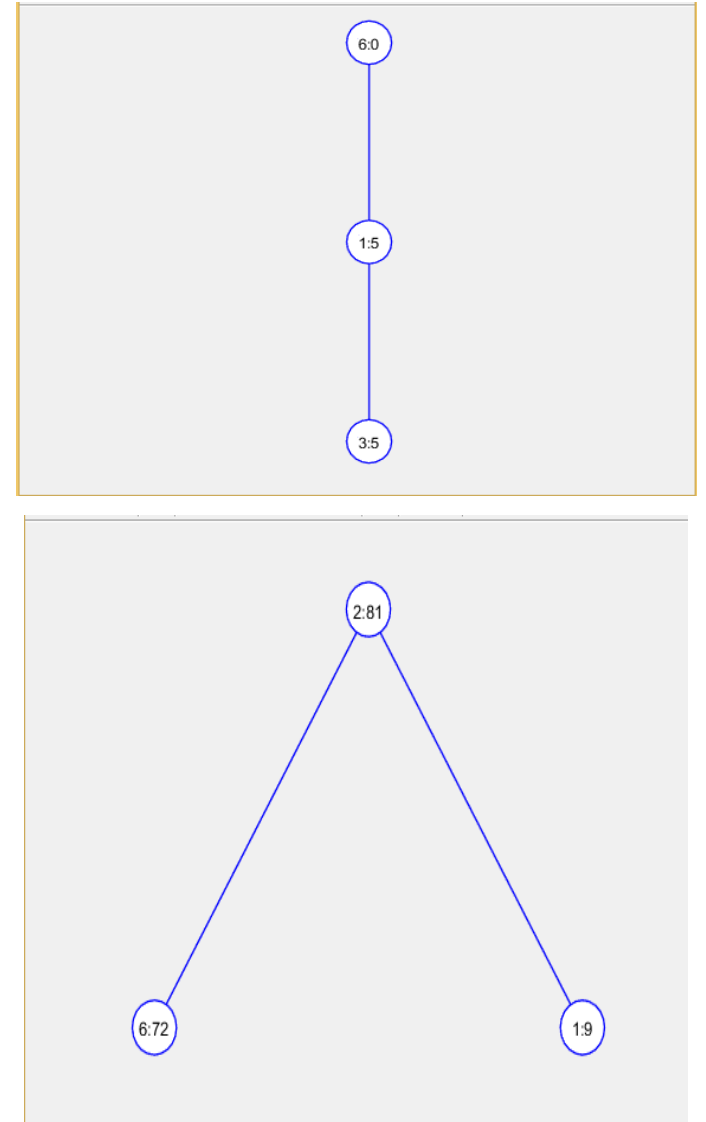

Fig. 3 (a\&b) Snapshot of MATLAB output of Main Modified Tree and Auxiliary Tree under Proposed Fast Modified FP-Growth algorithm

\subsection{Comparison Of Traditional Fp-Growth \& Proposed Modified Fp-Growth}

Both the algorithms tested for different size of transactions in Telecommunication datasets through MATLB. It is found that proposed algorithm is taking very less time than traditional FP-Growth algorithm and occupying less space than traditional-FP-Growth algorithm. The analysis of simulation result shows that the proposed Fast-Modified FP-Growth algorithm has a better detection as well as the faster rate of execution as compared to traditional FP-Growth algorithm(Fig-4). Accordingly proposed one will be better for generating association rules in data mining techniques on CRM datasets of Telecom Company.

\subsection{Classifying Telecom Data}

For classifying the Telecom data sets of a Company, different classification algorithm is used for predicting the churn for retention of customers and predicting the profit of Telecom Company. On measuring the performance, error and accuracy, the suitable classification algorithm is selected for predicting the profit of Telecom Company on churn prediction of customers for efficient managerial decision and making project plan to reach the related goals. The different classification algorithms are tested i.e. Naïve Bayasian Classifier, J48 Decision Tree, Random Tree for profit calculation using WEKA 3.8.2. Out of which Random Tree is more accurate having very less error rate for predication of profit(Fig-5). Hence "Random Tree" will be suitable, fast and easy to implement for predicting the future plan of Telecom customers and "J48 Decision Tree" is more accurate and suitable for churn prediction (Fig-7 \& Fig-8) by using this sample Telecomm data sets.

\subsection{AUC-ROC Curves for Performance Measurement}

In Machine Learning algorithm like classification, performance measurement is essential task. For visualizing the performance of the multi-class classification problem, AUC(Area Under The Curve) ROC (Receiver Operating Characteristics) curve is one of the most important evaluation metrics for checking the classification algorithm's performance. The ROC curve is plotted with TPR (True Positive Rate) against the FPR (False Positive Rate) where FPR is on the $\mathrm{x}$-axis and TPR is on the y-axis. Accordingly comparison of multiple Classifiers based on multiple Receiver Operating Characteristics (ROC) Curves for a two class problems i.e. churn (True) and no churn (False), it is observed that the closer the ROC Curve of model is to the diagonal line, the less accurate the model and good model shows likely to encounter true positive towards 1.0. Hence from the experiment under True (Churn) condition, the good ROC curve is of $\mathrm{J} 48$ Classification model and which is more accurate (Fig-10) for churn prediction.

Table. 1 Performance measurement of different models of classification for "Profit"

\begin{tabular}{|c|c|c|c|c|c|c|c|}
\hline Model & $\begin{array}{c}\text { Correctly } \\
\text { Classified } \\
\text { Inst.(\%) } \\
\text { (value) }\end{array}$ & $\begin{array}{l}\text { In Correctly } \\
\text { Classified } \\
\text { Inst.(\%) } \\
\text { (value) }\end{array}$ & $\begin{array}{l}\text { Time } \\
\text { Taken } \\
(\mathrm{sec})\end{array}$ & $\begin{array}{c}\text { TP } \\
\text { Rate }\end{array}$ & FP Rate & $\begin{array}{c}\text { F- } \\
\text { Measure }\end{array}$ & ROC \\
\hline $\begin{array}{c}\text { Random } \\
\text { Tree }\end{array}$ & $\begin{array}{r}99.166 \\
(119)\end{array}$ & $\begin{array}{c}0.833 \\
(1)\end{array}$ & 0 & 1.000 & 0.333 & 0.996 & 1.000 \\
\hline $\begin{array}{c}\mathrm{J} 48 \\
\text { Decision }\end{array}$ & $\begin{array}{l}97.5 \\
(117)\end{array}$ & $\begin{array}{l}2.5 \\
(3)\end{array}$ & 0.05 & 1.000 & 1.000 & 0.987 & 0.141 \\
\hline $\begin{array}{l}\text { Naïve } \\
\text { Bayes }\end{array}$ & $\begin{array}{r}96.666 \\
(116)\end{array}$ & $\begin{array}{c}3.333 \\
(4)\end{array}$ & 0.02 & 0.991 & 1.000 & 0.983 & 0.615 \\
\hline
\end{tabular}




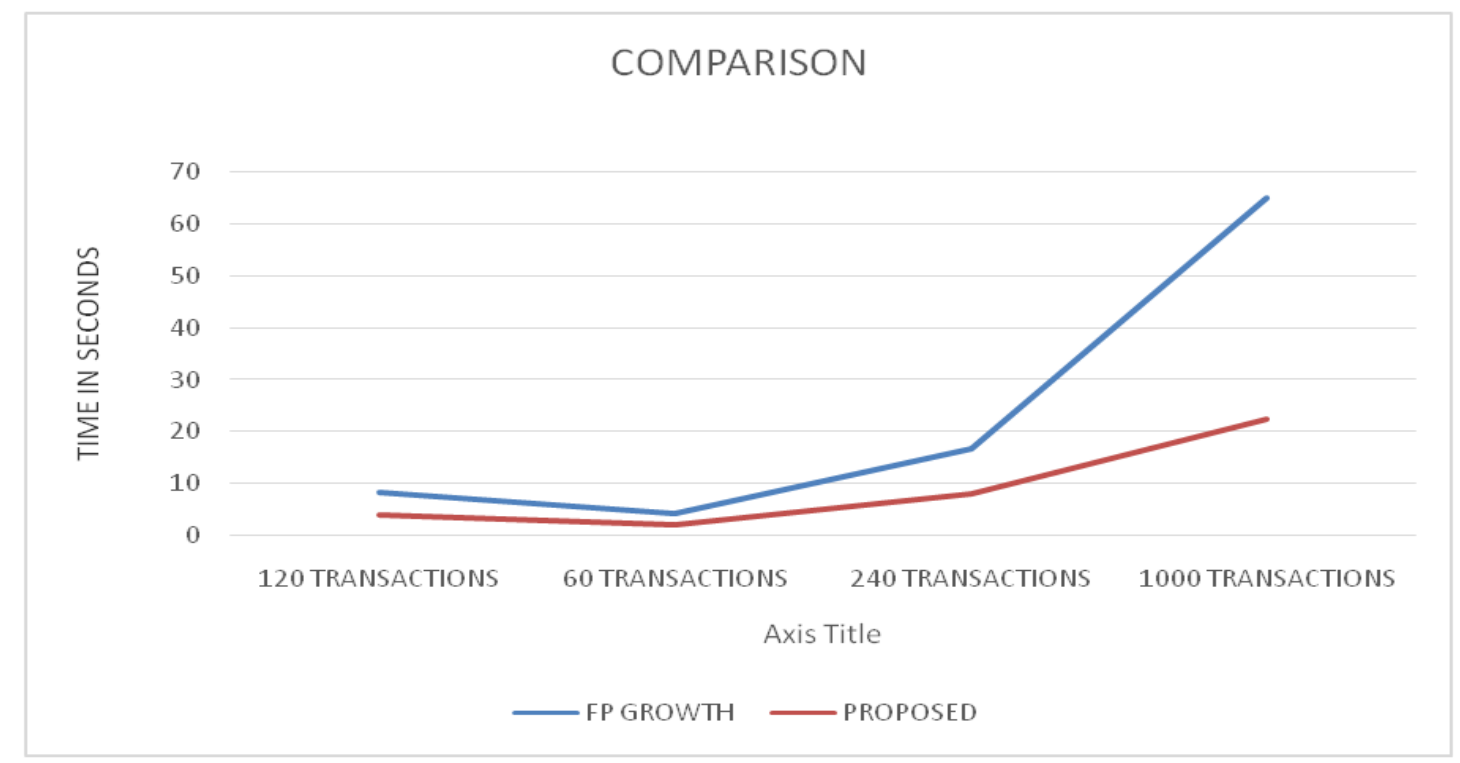

Fig. 4 Comparison of execution time

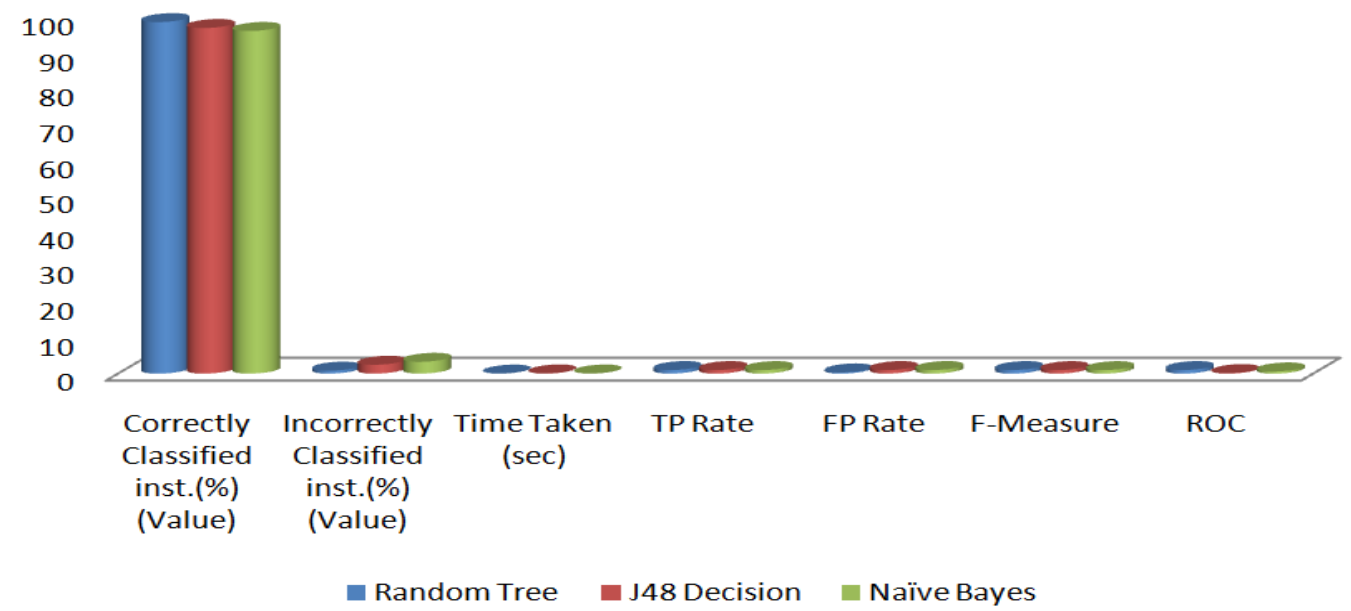

Fig.5 Profit analysis measurement between performance of different models

\section{ERROR ANALYSIS}

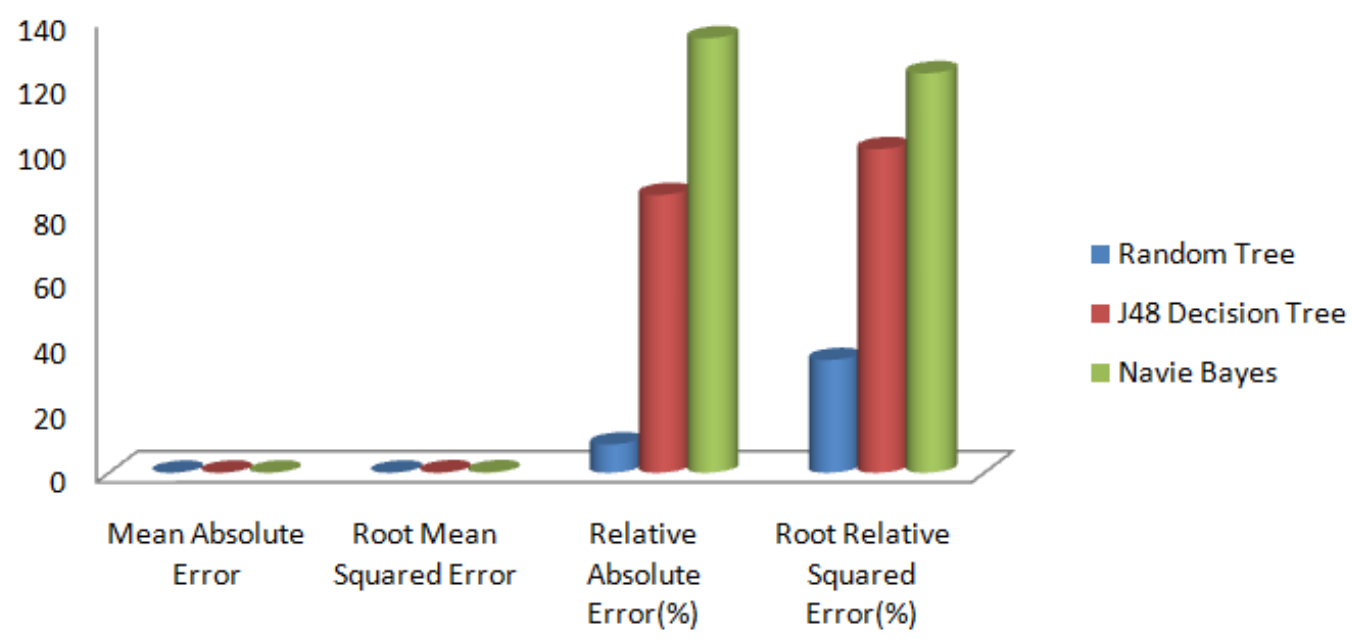

Fig.6 Error analysis of different models of Classification 


\section{FALSE CONDITION}

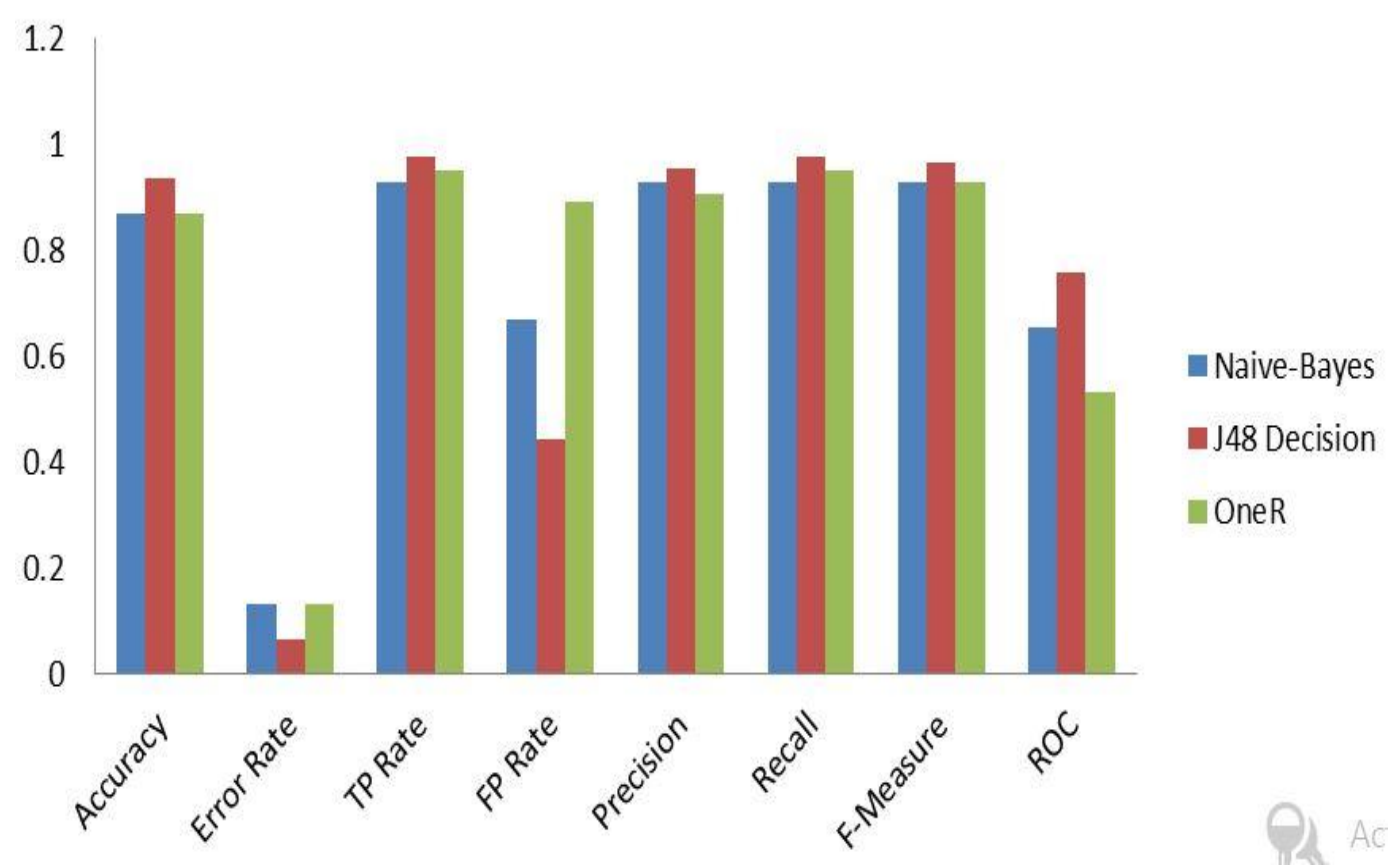

Fig.7 Analysis of "NO Churn" between different models.

\section{TRUE CONDITION}

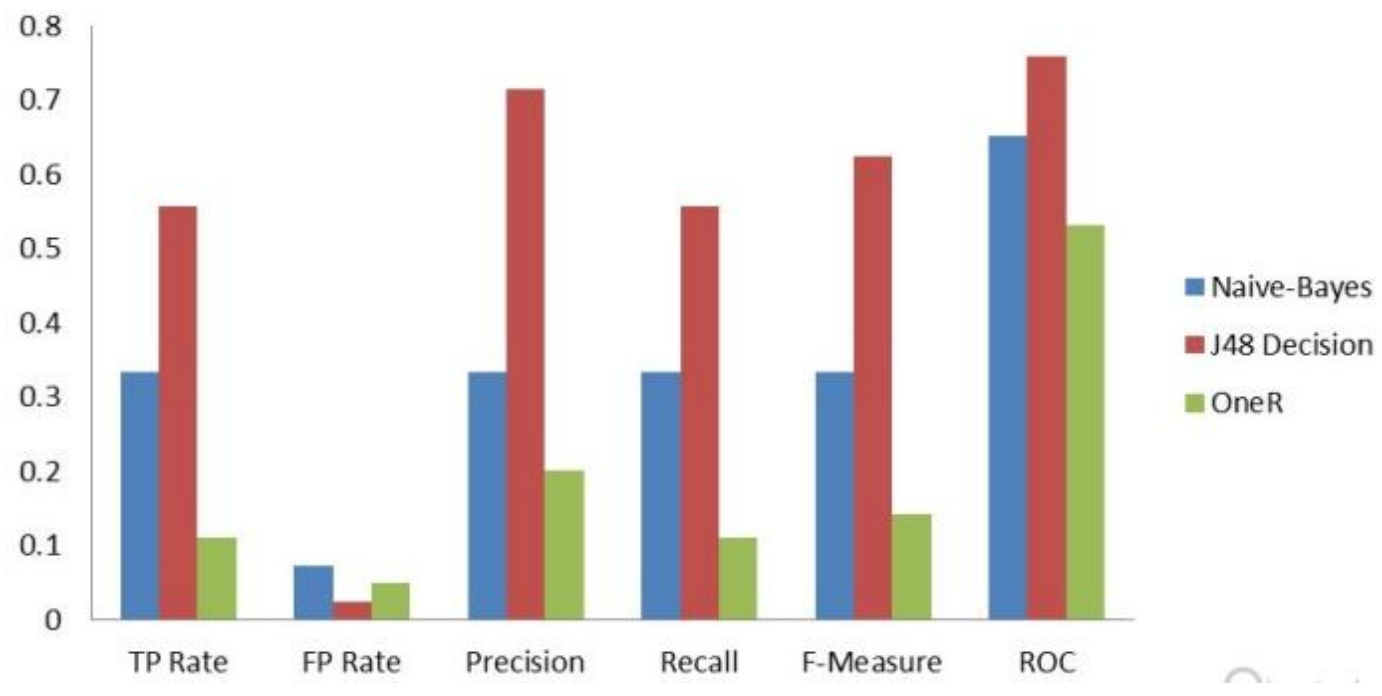

Fig.8 Analysis of "Churn" between different models

Table.2 Training \& Simulation of different models of classification

\begin{tabular}{|c|c|c|c|c|}
\hline $\begin{array}{c}\text { Algorithm } \\
\text { Total Instances } \\
(120)\end{array}$ & $\begin{array}{c}\text { Mean } \\
\text { Absolute } \\
\text { error }\end{array}$ & $\begin{array}{c}\text { Root } \\
\text { Mean } \\
\text { Squared } \\
\text { error }\end{array}$ & $\begin{array}{c}\text { Relative } \\
\text { Absolute } \\
\text { error(\%) }\end{array}$ & $\begin{array}{c}\text { Root } \\
\text { Relative } \\
\text { Squared error } \\
(\%)\end{array}$ \\
\hline Random Tree & 0.005 & 0.0548 & 8.7302 & 34.7909 \\
\hline J48 Decision Tree & 0.0491 & 0.1572 & 85.6849 & 99.8626 \\
\hline Navie Bayes & 0.0768 & 0.194 & 134.0658 & 123.2588 \\
\hline
\end{tabular}


Table.3 Performance measurement of different models of classification for "Churn"

\begin{tabular}{|c|c|c|c|c|c|c|c|c|c|}
\hline Model & Accuracy & Error Rate & TP Rate & FP Rate & Precision & Recall & F-Measure & ROC & Class \\
\hline Naive-Bayes & 0.8681 & 0.1318 & 0.927 & 0.667 & 0.927 & 0.927 & 0.927 & 0.652 & False \\
\hline & & & 0.333 & 0.073 & 0.333 & 0.333 & 0.333 & 0.652 & True \\
\hline J48 Decision & 0.9340 & 0.0659 & 0.976 & 0.444 & 0.952 & 0.976 & 0.964 & 0.759 & False \\
\hline & & & 0.556 & 0.024 & 0.714 & 0.556 & 0.625 & 0.759 & True \\
\hline OneR & 0.8681 & 0.1318 & 0.951 & 0.889 & 0.907 & 0.951 & 0.929 & 0.531 & False \\
\hline & & & 0.111 & 0.049 & 0.200 & 0.111 & 0.143 & 0.531 & True \\
\hline
\end{tabular}

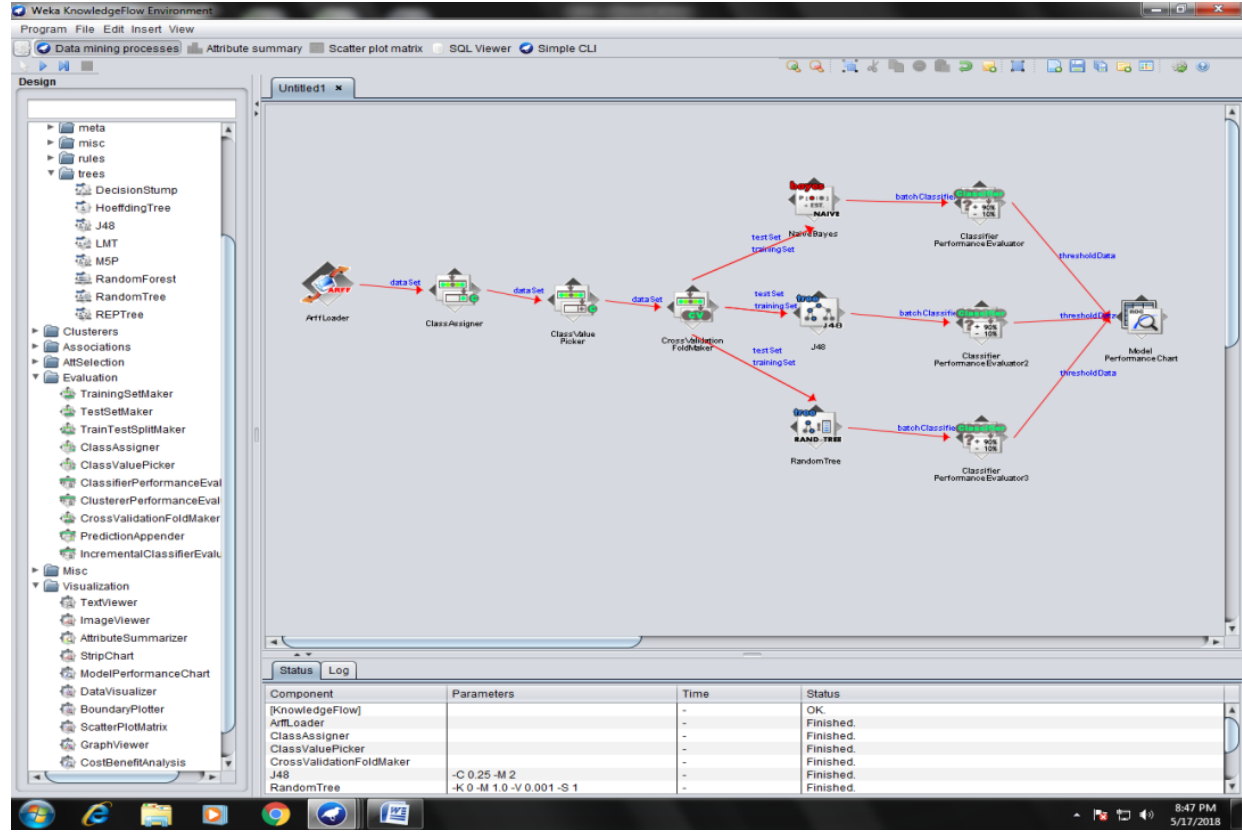

Fig.9 Designing of performance of three classifiers for ROC curves

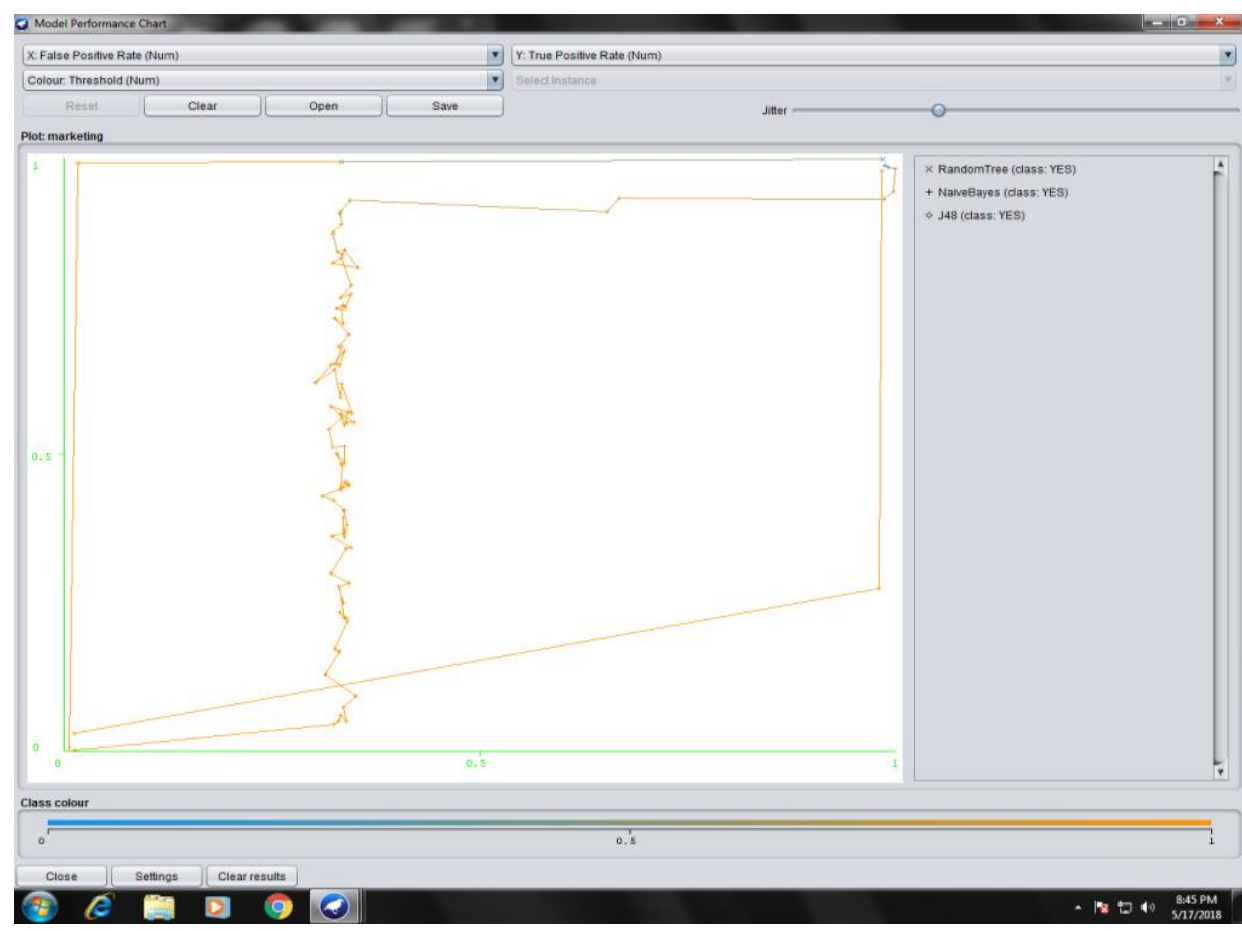

Fig.10 ROC curves generated by three classifier Models 


\section{CONCLUSION}

Existing model of Customer Relationship management (CRM) in Corporate Telecom Sector shows that for customer query and managerial decision through traditional searching systems used by SQL Server. Same will not serve the long term decision for market growth in the marketing epoch. Accordingly this paper proposed suitable data mining techniques i.e. Association and Classification considering processing overheads and time complexity. From the result analysis on Telecom CRM data-sets with proposed data mining techniques, it is concluded that, Fast Modified Frequent Pattern Growth (FMFPG) algorithm is the best for finding frequent item-sets in association data mining technique as it saves execution time and requires less memory space in comparison to traditional FP algorithm in association rule. Finally J48-Tree is proposed for predicting "Churn" in Telecom market \& Random-Tree is for predicting future "Profit" on available Telecom Plan under different models of classification techniques through evaluating the performance measurement of classifier while implementing and testing through WEKA-3.8.2.

\section{REFERENCES}

[1] Adam, Braff., Passmore, William,J. and Simpson, Michael (2006) "Going the distance with telecom customers" In the proceedings of The Mckinsey Quarterly,No.4, (pp.83).

[2] Ananthi, D., Karthiga, E., Vithiskumar, R.(2013) "Optimizing the CRM process in Product Market place by Association Rule Mining Technology" In the proceeding of Journal of Environmental Science Engineering \& Technology, Vol-2 (pp.412-416)

[3] Alawin, Ayman., Mohmmad, Al., aitah, ma., Balqua, Al (2014) " Proposed ranking for point of sales using data mining for Telecom Operations" In the proceeding of International Journal of Database management system,Vol-6.

[4] Bagozzi, Richard P.(1995). "Reflections on Relationship marketing in Consumer markets" In proceeding of Journal of the Academy of Marketing Science, 23(Fall), (pp. 272-277).

[5] Berry, 1., Shostack, G., and .Upah, G. (2003). "Emerging perspectives on service marketing", Chacago,IL, American marketing Association (pp.25-28).

[6] Bhave, Ashish (2002). "Customer Satisfaction Measurement" in the proceeding of Quality and Productive journal, ( pp.562-572).
[7] Chaturvedi, Mukesh., Chaturvedi, Abhinav (2005) "Customer Relationship Management-An India Perspective" In the proceeding of Excel Books,ISBN 10: 8174464565, ISBN 13: 9788174464560 ,New Delhi (pp36).

[8] Dahiya, Kiran., Talwar, Kanika (2015) "Customer Churn Prediction in Telecommunication Industry using Data mining technique-A Review" In the proceeding of International Journal of Advanced Research in Computer Science and Software Engineering, Vol-5, Issue-4.

[9] Heling, Jiang., Yang, An., Yan, Fengyun.,Hang, Miao (2016) "Research on pattern Analysis and data Classification methodology of Data mining and knowledge Recovery", In the proceeding of International journal of Hybrid Information Technology, IEEE, Vol-9( pp.179-186).

[10] Khan, M N., Rahman, Abdur (2017) "An Assessment of data mining based CRM techniques for enhancing profitability" In proceeding of Association of Modern Education \& Computer science, (pp.30-40).

[11] Meltzer, Michael."Are your customer profitable and segment your customer based on profitability"

[12] Pradnya, A., Shirasth, Verma, Vijaya Kumar (2013) “ A recent Survey on Incremental Temporal Association Rule Mining" In the proceeding of International Journal of Innovative Technology \& Exploring Engineering, Vol3,Issue-1( pp.88-90).

[13] Sasikala (2006) "Telecom Services: Measurement of Customer satisfaction" In the proceeding of The ICFAI, Journal of Management Research,Vol-5,Issue-10 (pp.35$53)$.

[14] Srivastava, R., Bhangde, Jatin., Bhatt, Nirav., Gogri, Kunal and Marfatia, Hemat (2006) " Role of Competition in Growing Markets: Telecom Sector” In the proceeding of Indian Journal of Marketing ( $p p-8)$.

[15] Senkamalavalll, R., Dr. Bhubaneswari,T (2013)“Data mining techniques for CRM" In the proceeding of International journal of Scientific \& Engineering Research, Vol-4, Issue-4, (pp. 509-513).

[16] Tejaswini, Hilage, Kulkarni, R.V (2012)" Review the literature of Data Mining" In the proceeding of IJRRS, Vol-II ( PP.107-114). 